\title{
Numerical Analysis On Truss Bridge Performance Due To Structural Elements Strength Reduction
}

\author{
Hajar Dwianandha Octariasari ${ }^{1}$, Winda Tri Wahyuningtyas ${ }^{2}$, M. Farid Ma'ruf ${ }^{2^{*}}$ \\ Undergraduate student, Civil Engineering Dept., Engineering Faculty, Jember University ${ }^{1}$ \\ Lecturer, Civil Engineering Dept., Engineering Faculty, Jember Universiyt ${ }^{2}$ \\ Coresponding author: farid.teknik@unej.ac.id
}

\begin{abstract}
Structural element deterioration of truss bridge will change the performance of the system. Earlier identification leads to better bridge maintenance program to prevent bridge failure. A numerical analysis has been employed to truss bridge. Structural element damage was modeled by applying strength reduction on the element through reducing its cross area. Truss bridge with various single structural element strength reductions up to $20 \%$ was simulated. The bridge performance was evaluated based on the induced deflection. The results show that the onset of maximum deflection is the middle of the span and is independent of the element to which the strength reduction employed. Meanwhile, the impacted element experiences increasing moment after strength reduction.
\end{abstract}

Keywords: truss bridge, strength reduction, deflection, numerical analysis

\section{INTRODUCTION}

B ridge deterioration occurs prior to its failure. It usually takes long time from structural element damage to bridge failure. That's why bridge monitoring is very important to identify early structural element problem before leading to bridge failure. The problem can be caused by changes in structural characteristics of the bridge, including changes in structural geometry [1].

Non-destructive method for bridge monitoring can visually predict the structural problem but requires longer time and higher cost [2]. Vibration test is the famous non-destructive method to identify structural element damage. It can be applied for truss and plate checking [3]. The installment of sensors is able to record the response of bridge element and generates structural condition report [4].

Khusaibi simulate numerical analysis to model bridge behaviour when the strength of the structural element reduces due to overload vehicle induced crack [5]. The conducted research separately regarding the corrotion of the steel bridge element [6]. They both worked on numerical analysis and modeled the corrotion effect through reducing the element cross section. The results agree each other that bridge stability decreased significantly with decreasing cross area.

Nyarko conducted laboratory scale test on the steel truss bridge by removing an element of structure [7]. He compared the result with finite element analysis. He succeeded to identify the critical bar and the deformation increment due to the element removal.

This work simulates numerically the steel truss bridge to identify its behavior during structural element strength reduction. The strength reduction was applied to various structural element. The behaviour of the truss due to various structural element deterioration was evaluated in deep.

\section{METHOD}

A simple steel truss was modeled and evaluated using 3D finite element software. The model and element number are presented in Figure 1. The bridge was supported by one roller and one pin joint. It had 60 $\mathrm{m}$ span and $9 \mathrm{~m}$ of both width and height. WF.700.300.13.24 of steel was utilized. The detail of material properties is shown in Table 2. While Table 3 describes the working load applied.

The structural element strength reduction was applied by decreasing the element cross section through scaling the dimension down proportionally. Strength reduction was employed to 14 cross girders interchangeably. The employed element cross section decreased 5\%,10\%, 15\%, and $20 \%$. Table 1 presents the simulation scenario and list of the employed elements. Figure 2 shows the elements to which strength reduction employed. 




Figure 1. Steel truss bridge model

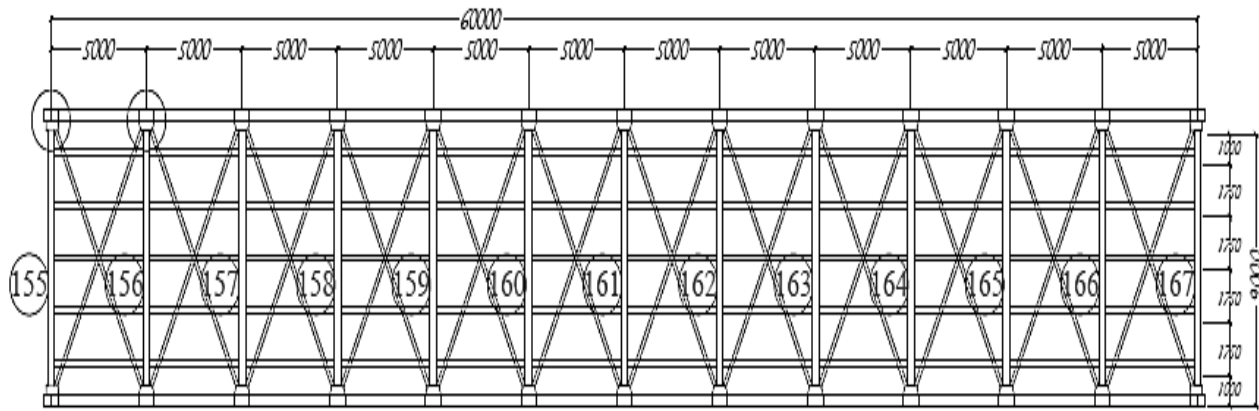

Figure 2. Strength reduction employed cross girders

Table 1.

Simulation scenario

\begin{tabular}{|c|c|c|}
\hline Type & Element number & Strength reduction \\
\hline Type 1 & \multicolumn{2}{|c|}{$\begin{array}{c}\text { Initial conditions with the load without being } \\
\text { destroyed }\end{array}$} \\
\hline Type 2 & 155 & $5 \%, 10 \%, 15 \%, 20 \%$ \\
\hline Type 3 & 156 & $5 \%, 10 \%, 15 \%, 20 \%$ \\
\hline Type 4 & 157 & $: 5 \%, 10 \%, 15 \%, 20 \%$ \\
\hline Type 5 & 158 & $5 \%, 10 \%, 15 \%, 20 \%$ \\
\hline Type 6 & 159 & $5 \%, 10 \%, 15 \%, 20 \%$ \\
\hline Type 7 & 160 & $5 \%, 10 \%, 15 \%, 20 \%$ \\
\hline Type 8 & 161 & $5 \%, 10 \%, 15 \%, 20 \%$ \\
\hline Type 9 & 162 & $5 \%, 10 \%, 15 \%, 20 \%$ \\
\hline Type 10 & 163 & $5 \%, 10 \%, 15 \%, 20 \%$ \\
\hline Type 11 & 164 & $5 \%, 10 \%, 15 \%, 20 \%$ \\
\hline Type 12 & 165 & $5 \%, 10 \%, 15 \%, 20 \%$ \\
\hline Type 13 & 166 & $5 \%, 10 \%, 15 \%, 20 \%$ \\
\hline Type 14 & 167 & $5 \%, 10 \%, 15 \%, 20 \%$ \\
\hline
\end{tabular}

Table 2

The properties of WF.700.300.13.24
Table 3

Moment, shear and force generated after $20 \%$ cross section reduction

\begin{tabular}{|c|c|c|c|c|}
\hline Rank & $\begin{array}{l}\text { Element } \\
\text { number }\end{array}$ & $\begin{array}{l}\text { Moment } \\
\text { Value } \\
(\mathrm{Kgm})\end{array}$ & $\begin{array}{c}\text { Shear Stress } \\
(\mathrm{Kgm})\end{array}$ & $\begin{array}{l}\text { Axial } \\
\text { Force } \\
(\mathrm{Kgm})\end{array}$ \\
\hline 1 & 161 & $131.904,58$ & 68974,1 & $33.015,67$ \\
\hline 2 & 160 & $100.415,35$ & 52856,2 & $32.998,62$ \\
\hline 3 & 162 & $100.410,22$ & 52872 & $31.492,81$ \\
\hline 4 & 165 & $87.887,30$ & 47438,7 & $30.05,09$ \\
\hline 5 & 157 & $87.465,07$ & 47157,7 & $29.988,29$ \\
\hline 6 & 164 & $85.838,44$ & 46598,6 & $24.405,69$ \\
\hline 7 & 158 & $85.763,08$ & 46507,3 & $24.107,25$ \\
\hline 8 & 159 & $84.850,82$ & 45980,1 & $17.820,06$ \\
\hline 9 & 163 & $84.833,87$ & 46008,3 & $17.296,90$ \\
\hline 10 & 156 & $82.757,46$ & 45401,6 & $16.389,41$ \\
\hline 11 & 166 & $82.376,28$ & 45031,4 & $11.739,13$ \\
\hline 12 & 155 & $59.215,78$ & 24164,5 & $4.084,68$ \\
\hline 13 & 167 & $52.852,21$ & 23181,4 & $1.278,56$ \\
\hline
\end{tabular}

\begin{tabular}{lcc}
\hline \multicolumn{1}{c}{ Parameters } & Value & Unit \\
\hline Cross Section Area (A) & 0.02355 & $\mathrm{~m}^{2}$ \\
Young's Modulus (E) & $2 \times 10^{6}$ & $\mathrm{MPa}$ \\
Inertia (I) & 0.00194 & $\mathrm{~m}^{4}$ \\
Unit Weight $(\rho)$ & 78500 & $\mathrm{~N} / \mathrm{m}^{3}$ \\
\hline
\end{tabular}




\section{SIMULATION RESULTS}

The simulation results shows that moment, shear stress, and axial force generated during simulation increased at the element to which the strength reduction employed. It is true since moment and shear stress inversely proportional with the inertia of the element. While the inertia decrease with decreasing the cross section. The largest moment and shear increment occur when the reduction applied at element 161 . This element located in the middle of the span. The list of element which cause biggest moment, shear and axial stress increment is presented in Table 3 .

Deflection of bridge system increase with decreasing element strength. Element 161 which is in the middle of the span again generated the largest deflection when the reduction employed. The most interesting finding is that the onset of maximum deflection is independent of the strength reduction employed element. It is in the middle of the span. It means that the middle of the span is the most critical part of the bridge. The research only uses the results of the program structure in the form of deflection.

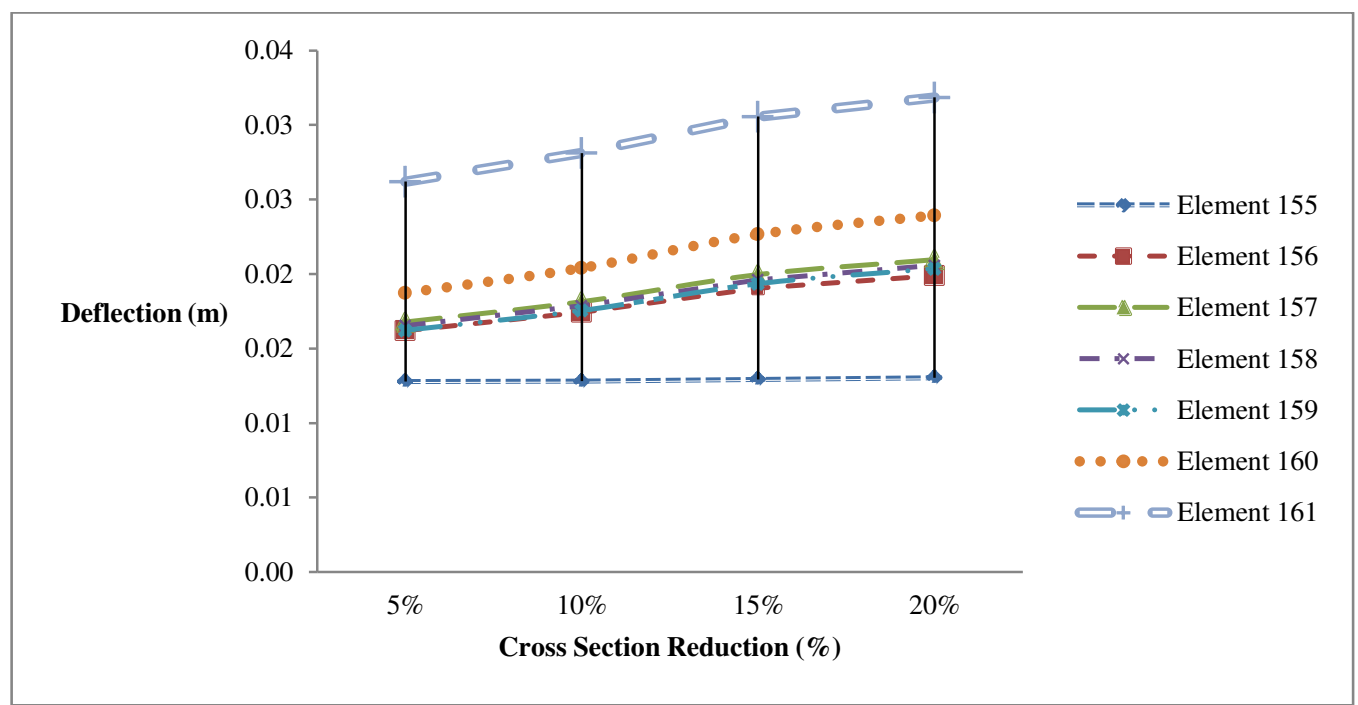

Figure 3. Variation of bridge deflection during various element strength reduction

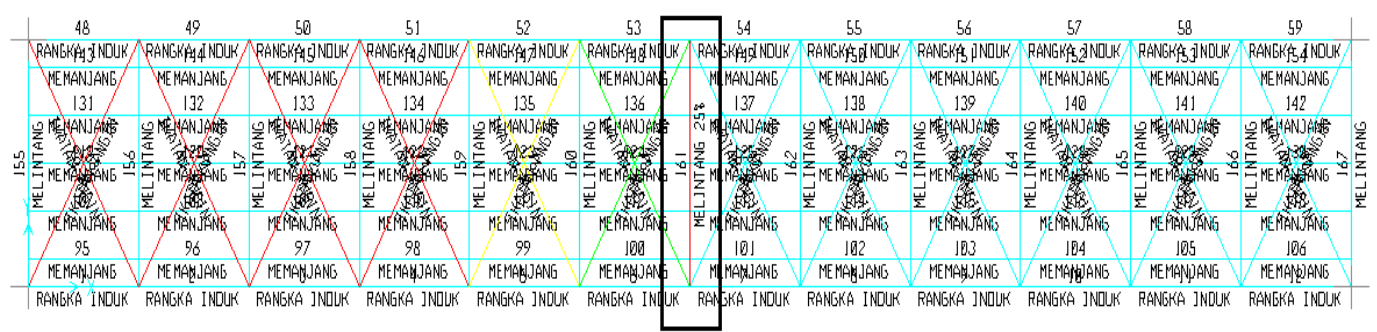


Table 4. Ranking of Shear, Moment and Deflection Values in Elements with a Reduction of Area Size 5\%, 10\%, 15\%, 20\% and 25\%.

\begin{tabular}{|c|c|c|c|c|c|}
\hline \multirow[t]{2}{*}{ Element That Are Destroyed } & \multicolumn{5}{|c|}{ Ranking Of Critical Element } \\
\hline & $5 \%$ & $10 \%$ & $15 \%$ & $20 \%$ & $25 \%$ \\
\hline \multirow{3}{*}{155} & 161 & 161 & 161 & 161 & 161 \\
\hline & 160 & 160 & 160 & 160 & 160 \\
\hline & 155 & 155 & 155 & 155 & 155 \\
\hline \multirow{3}{*}{156} & 161 & 161 & 161 & 161 & 161 \\
\hline & 160 & 160 & 160 & 160 & 160 \\
\hline & 156 & 156 & 156 & 156 & 156 \\
\hline \multirow{3}{*}{157} & 161 & 161 & 161 & 161 & 161 \\
\hline & 160 & 160 & 160 & 160 & 160 \\
\hline & 157 & 157 & 157 & 157 & 157 \\
\hline \multirow{3}{*}{158} & 161 & 161 & 161 & 161 & 161 \\
\hline & 160 & 160 & 160 & 160 & 160 \\
\hline & 158 & 158 & 158 & 158 & 158 \\
\hline \multirow{3}{*}{159} & 161 & 161 & 161 & 161 & 161 \\
\hline & 160 & 160 & 160 & 160 & 160 \\
\hline & 159 & 159 & 159 & 159 & 159 \\
\hline \multirow{3}{*}{160} & 161 & 161 & 161 & 161 & 161 \\
\hline & 160 & 160 & 160 & 160 & 160 \\
\hline & 155 & 155 & 155 & 155 & 155 \\
\hline \multirow{3}{*}{161} & 161 & 161 & 161 & 161 & 161 \\
\hline & 160 & 160 & 160 & 160 & 160 \\
\hline & 155 & 155 & 155 & 155 & 155 \\
\hline
\end{tabular}

\section{CONCLUSION}

The numerical analysis on the bridge system behavior due to element strength reduction was conducted. The results showed hat whichever element get employed the strength reduction, element 161 will experience the largest moment, shear and axial force. The onset of the largest deflection is in the middle of the span, independent of the location to which strength reduction employed. This simulation shows that numerical analysis is useful to identify the critical element to which bridge monitoring should focus deeper.

\section{REFERENCES}

[1] C. Farrary, R and D. A. Jaureguiz, "Comparative Study Of Damage Identification Algorithms Applied
To A Bridge," Smart Mater. Struct, vol. 7, pp. 704 719, 1998.

[2] P. C. Chang, A. Flatau, and S. C. Liu, "Health Monitoring of Civil Infrastructure," IEEE, vol. 2, p. 257, 2003.

[3] X. H. Zhang, Y. L. Xu, and S. Zhan, "Optimal Locations Of A Multi-Type Sensor System For Structural Health Monitoring," in Proceedings Of The 8th International Conference On Structural Dynamics, 2011.

[4] R. St. Hou, Z., Noori, M., dan Arnand, "WaveletBased Approach For Structural Damage Detection," J. Eng. Mech., vol. 126, no. 7, 2000.

[5] H. A. Khusaibi, "Truss Bridge Analysis - Truck Weights," Eng. Mech., vol. 461, 2007.

[6] T. Tamakoshi, M. Ishio, F. Miyahara, Y. Yokoi, and M. Shirat, "Finite Element-Level Bridge Inspection Data Analysis And Experiments On The Durability Of Rc Deck," 2006.

[7] Nyarko, Otchere, and J. Kwabena, "Model Test and Numerical Simulation for Structural Health Monitoring of Truss Bridge,” 2011. 